\title{
Lost in a Nameless Chaos-Women's Experiences of Postpartum Depression: A Meta-Ethnographic Study
}

\author{
Bente Dahl*, Marthe Sandvoll Hermansen, Elisabeth Severinsson \\ The Centre for Women's, Family and Child Health, Department of Nursing and Health, Faculty of Health and Social Sciences, \\ University College of Southeast Norway, Kongsberg, Norway \\ Email: ^bente.dahl@usn.no
}

How to cite this paper: Dahl, B., Hermansen, M. and Severinsson, E. (2017) Lost in a Nameless Chaos-Women's Experiences of Postpartum Depression: A Meta-Ethnographic Study. Open Journal of Nursing, 7, 962977.

https://doi.org/10.4236/ojn.2017.78071

Received: July 17, 2017

Accepted: August 27, 2017

Published: August 30, 2017

Copyright $\odot 2017$ by authors and Scientific Research Publishing Inc. This work is licensed under the Creative Commons Attribution International License (CC BY 4.0).

http://creativecommons.org/licenses/by/4.0/

c) $\underset{\mathrm{EY}}{\mathrm{i}}$ Open Access

\begin{abstract}
Postpartum depression is a common complication related to childbearing with an estimated prevalence of $10 \%-15 \%$. The aim of the study was to explore and synthesize qualitative empirical studies published between 2005 and 2016 that describe women's experiences of postpartum depression. Ten qualitative studies describing different perspectives on women's experiences of postpartum depression were summarized and synthesized using Noblit and Hare's 7-step meta-ethnographical method. Four central metaphors described women's experiences of postpartum depression: Feeling trapped by reality, Experiencing a nameless chaos, Struggling to find a way out and Being seen as a normal but suffering person. The findings resulted in the following synthesis: The women expected the transition to motherhood to be a joyous experience. Instead, they found it painful, lonely and experienced losing themselves in a nameless chaos. Motherhood is challenged when women experience losing themselves due to depression rather than building a new identity as a mother. Such a situation causes chaos, shame, anxiety and isolation. When seeking professional help, it is essential that the woman is encountered with empathy and professional knowledge, rather than a pat on the back and an underestimation of her problems.
\end{abstract}

\section{Keywords}

Postpartum Depression, Experience, Meta-Ethnography, Qualitative

\section{Introduction}

Postpartum depression (PPD) is a mental disorder and a common complication 
related to childbearing [1] [2]. The disorder is referred to as a major depressive episode with a postpartum onset in the International Statistical Classification of Diseases (ICD-10) [3] or with a peripartum onset in the Diagnostic and Statistical manual of Mental Disorders, (DSM-5) [4]. However, studies have demonstrated that this narrowly defined time frame should be broadened [5] [6] and according to Munk-Olsen et al. [7], first-time mothers are at increased risk of postpartum mental disorders for several months after the birth.

The estimated prevalence of postpartum depression ranges from 10\% - 15\% [7]. Risk factors for developing the disorder include previous psychopathology, lack of support from partner, low socio-economic status, domestic violence, history of abuse and life stress [6]. Pregnancy and birth related complications, such as untreated depression and anxiety in pregnancy, have also been mentioned as possible contributory factors [2] [6].

In addition to maternal suffering and diminished functioning, studies have shown that PPD is associated with poor mother-infant attachment. Furthermore, infants whose mothers suffered from postnatal depression are at increased risk of developing emotional problems as well as problems related to social behavior [8]. The association between postnatal depression and cognitive outcomes in the child is also described and includes learning abilities and language development [8]. Two meta-studies present women's experiences of PPD [9] [10]. Beck's meta-synthesis on PPD published in 2002 includes 18 qualitative papers on the subject [9], while Knudson-Martin and Silverstein's [10] meta-data-analysis published in 2009 includes nine qualitative papers. These papers contain a total of 27 empirical studies published between 1990 and 2005 that describe women's experiences of PPD as related to lack of congruity between expectations and experiences of motherhood, loss of identity and role as well as feelings of "losing oneself". Feelings of anxiety, despair and sadness were also referred to in the studies. According to the mothers, the responsibility of motherhood was overwhelming and they were afraid that they would be unable to deal with their new role. They described feelings of shame and guilt connected to the disorder and in order to avoid being regarded as a failure, they isolated themselves or refrained from talking about their feelings with friends and healthcare providers.

\section{Aim}

Beck and Knudson-Martin's meta-studies [9] [10] include empirical studies that provide a limited but important snapshot of knowledge about women's experiences of PPD from 1990 to 2005. However, we ask whether women described similar experiences in studies published after 2005 and if the information contributed by recent empirical studies is likely to change our understanding of the experience of suffering from PPD. We therefore conducted a study to explore and synthesize qualitative empirical studies published between 2005 and 2016 that describe women's experiences of postpartum depression. 


\section{Methods}

\subsection{Design}

In order to synthesize qualitative research findings we conducted a meta-synthesis, using a meta-ethnographic approach [11]. The use of meta-synthesis has become increasingly popular in health-related research [12] as it is supposed to provide a new, integrated and more complete interpretation of the findings, offering an in-depth understanding that transcends the sum of the individual studies and facilitates theory development [13]. Several ways of conducting a qualitative meta-synthesis have been described [14]. In this study, our aim was not to summarize or aggregate data, but to conduct an interpretive integration of the empirical data from the included studies [14]. Thus, due to its interpretive orientation we decided to use meta-ethnography, a method developed by Noblit and Hare [11] comprising seven overlapping and sometimes parallel steps, as described in Table 1.

\subsection{Data Collection and Participants}

\subsubsection{Search Strategy and Outcome}

We started by defining the aim of the study and deciding on inclusion and exclusion criteria. We continued by performing a scope search to gain a preliminary overview of the research area and to identify relevant search terms. The scope search was followed by a systematic literature search in March 2016. An experienced librarian guided the literature search, which included the PsycINFO, Cinahl, Pubmed and Maternity \& Infant Care databases. We applied the following search terms as MESH terms or text words, entered individually or in combination: postpartum depression, experience and emotions.

The literature search resulted in 962 hits. We started by excluding duplicates and studies that did not meet the inclusion criteria in terms of publication year, language and methods, after which 128 papers remained. We continued by manually examining all papers, excluding those that were thematically or methodologically irrelevant. We also identified and excluded another 11 duplicates.

Table 1. The seven steps in meta-ethnography [11].

1) Getting started-identifying the topic of the study and defining the aim.

2) Deciding what is relevant to the initial interest-including relevant studies, describing search strategy and criteria for inclusion and exclusion.

3) Reading the studies - repeated reading of studies noting their interpretative metaphors.

4) Determining how the studies are related-determining the relationship between the studies.

This phase starts with the creation of a list of key metaphors (themes, concepts, phrases, ideas) and ends with an initial assumption that their relationship is reciprocal (findings across studies are comparable), refutational (findings stand in opposition to each other) or representative of a line of argument.

5) Translating the studies into one another-comparing metaphors and their interactions within single studies and across studies, while at the same time protecting uniqueness and holism.

6) Synthesizing translations-creating a new whole from the sum of the parts, enabling a second level of synthesis.

7) Expressing the synthesis-finding the appropriate form to effectively communicate the synthesis to the audience. 
The remaining papers were screened in the final two steps, resulting in the exclusion of an additional 24 papers. A further three papers were identified via backchaining. A detailed description of this process is presented in Figure 1.

\subsubsection{Inclusion and Exclusion Criteria}

Inclusion criteria: Qualitative empirical papers, written in English or Scandinavian languages, published in scientific peer-reviewed journals, published from 2005-2016, conducted in Western cultures, presenting different perspectives that were possible to separate (experiences of living with PPD, treatment and coping strategies).

Exclusion criteria: Papers with samples including women who had been previously diagnosed as suffering from mental health problems, papers presenting studies conducted in Non-Western cultures, published before 2005, written in languages other than English and the Scandinavian languages, quantitative studies, theoretical papers and dissertations [16]-[25].

\subsubsection{Quality Appraisal}

The first and second authors assessed the included papers [16]-[25] independently, guided by the Critical Appraisal Skills Programme (CASP) checklist [26]. This checklist is designated an educational and pedagogical tool without a scoring system. However, for our purpose it worked as a systematic reminder of issues related to the quality of a study, such as the aim, methodology, recruitment

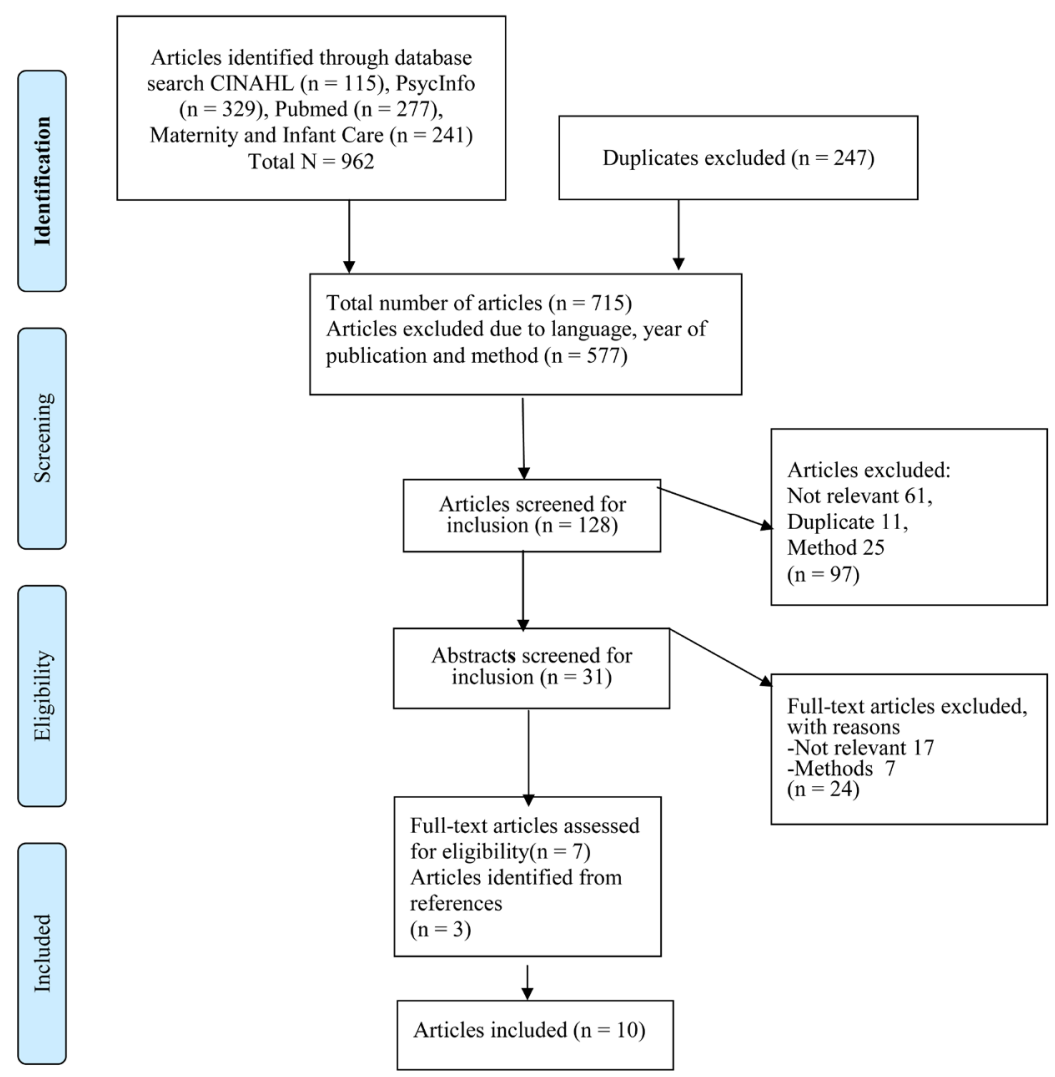

Figure 1. Overview of the search strategy using the PRISMA [15] flow diagram. 
strategy, data collection, reflexivity, ethical issues, data analysis, statement of the findings and the contribution of the study. We considered that two studies were of medium quality [22] [24] and that all the others were of high quality. All studies were therefore included [16]-[25]. A detailed list of the quality appraisal is shown in Table 2.

\subsection{Analysis and Synthesis}

Noblit and Hare [11] described three options for synthesizing studies, depending on how the study findings relate to one another. They refer to these options as "reciprocal synthesis", meaning that the accounts are directly comparable, or "refutational synthesis", meaning that the accounts stand in opposition to each other. A third option for synthesis occurs when the studies in combination represent a "line of argument". A line of argument synthesis is about inference or "What can be said about the whole (organization, culture, etc.) based on the selective studies of the parts?" [11] (p. 62).

When conducting the meta-ethnography, we considered the results sections in the primary studies as our data material. The analysis started with two of the authors separately reading all the included articles and identifying an index paper [25] characterized by good methodological quality and rich data material. We then reread the papers and noted the key metaphors relevant to the aim of the study. Noblit and Hare [11] used the concept of key metaphor to describe what other researchers usually refer to as themes, perspectives or concepts. We

Table 2. Critical Appraisal Skills Programme (CASP) [26] qualitative research checklist.

\begin{tabular}{|c|c|c|c|c|c|c|c|c|c|c|}
\hline & 16 & 17 & 18 & 19 & 20 & 21 & 22 & 23 & 24 & 25 \\
\hline $\begin{array}{l}\text { 1. Was there a clear statement of the aims of } \\
\text { the research? }\end{array}$ & $\mathrm{Y}$ & $\mathrm{Y}$ & $\mathrm{Y}$ & $\mathrm{Y}$ & $\mathrm{Y}$ & $\mathrm{Y}$ & $\mathrm{Y}$ & $\mathrm{Y}$ & $\mathrm{Y}$ & $\mathrm{Y}$ \\
\hline 2. Is a qualitative methodology appropriate? & $\mathrm{Y}$ & $\mathrm{Y}$ & $\mathrm{Y}$ & $\mathrm{Y}$ & $\mathrm{Y}$ & $\mathrm{Y}$ & $\mathrm{Y}$ & $\mathrm{Y}$ & $\mathrm{Y}$ & $\mathrm{Y}$ \\
\hline $\begin{array}{l}\text { 3. Was the research design appropriate to } \\
\text { address the aims of the research? }\end{array}$ & $\mathrm{Y}$ & $\mathrm{Y}$ & $\mathrm{Y}$ & $\mathrm{Y}$ & Y- & $\mathrm{Y}$ & Y- & $\mathrm{Y}$ & Y- & $\mathrm{Y}$ \\
\hline $\begin{array}{l}\text { 4. Was the recruitment strategy appropriate } \\
\text { to the aims of the research? }\end{array}$ & Y- & $\mathrm{Y}$ & Y- & $\mathrm{Y}$ & $\mathrm{Y}$ & $\mathrm{Y}$ & Y- & $\mathrm{Y}$ & $\mathrm{Y}$ & Y- \\
\hline $\begin{array}{l}5 . \text { Was the data collected in a way that } \\
\text { addressed the research issue? }\end{array}$ & $\mathrm{Y}$ & $\mathrm{Y}$ & $\mathrm{Y}$ & $\mathrm{Y}$ & $\mathrm{Y}$ & Y- & Y- & Y- & Y- & Y- \\
\hline $\begin{array}{l}\text { 6. Has the relationship between researcher } \\
\text { and participants been adequately considered? }\end{array}$ & $\mathrm{Y}$ & $\mathrm{N}$ & $\mathrm{Y}$ & $\mathrm{N}$ & $\mathrm{Y}$ & $\mathrm{N}$ & $\mathrm{N}$ & $\mathrm{N}$ & $\mathrm{N}$ & $\mathrm{Y}$ \\
\hline $\begin{array}{l}\text { 7. Have ethical issues been taken into } \\
\text { consideration? }\end{array}$ & $\mathrm{Y}$ & $\mathrm{Y}$ & $\mathrm{Y}$ & $\mathrm{Y}$ & $\mathrm{Y}$ & $\mathrm{Y}$ & $\mathrm{Y}$ & $\mathrm{Y}$ & $\mathrm{Y}$ & $\mathrm{Y}$ \\
\hline 8. Was the data analysis sufficiently rigorous? & $\mathrm{Y}$ & $\mathrm{Y}$ & $\mathrm{Y}$ & $\mathrm{Y}$ & $\mathrm{Y}$ & $\mathrm{Y}$ & $\mathrm{Y}$ & $\mathrm{Y}$ & $\mathrm{Y}$ & $\mathrm{Y}$ \\
\hline 9. Is there a clear statement of findings? & $\mathrm{Y}$ & $\mathrm{Y}$ & $\mathrm{Y}$ & Y- & $\mathrm{Y}$ & $\mathrm{Y}$ & $\mathrm{Y}$ & Y- & $\mathrm{Y}-$ & $\mathrm{Y}$ \\
\hline 10. How valuable is the research? & $\mathrm{Y}$ & $\mathrm{Y}$ & $\mathrm{Y}$ & $\mathrm{Y}$ & $\mathrm{Y}$ & $\mathrm{Y}$ & $\mathrm{Y}$ & $\mathrm{Y}$ & $\mathrm{Y}$ & $\mathrm{Y}$ \\
\hline
\end{tabular}

( $\mathrm{Y}=\mathrm{Yes}, \mathrm{N}=\mathrm{No}$ ). Comments: 3-Choice of design not argumented: 20, 22, 24; 4-Discussion of recruitment not included: 16, 18, 22, 25; 5-Methods for data collection not argumented and/or Setting not described and/or Data saturation not discussed: 21, 22, 23, 24, 25; 6-Reflexivity discussion not included: 17, 19, 21, 22, 23, 24; 9-A thorough limitations discussion not included: 19, 23, 24. 
placed the key metaphors in a grid, retaining the terminology used by the primary authors, which revealed that the studies were similar. In the next step, we translated issues from the same row into a common concept by reciprocal translation [11], comparing themes in the first paper with those in the next until all papers were covered. Noblit and Hare [11] called the sixth step in the meta-ethnographic approach "synthesizing translations", where synthesis "refers to making a whole into something more than the parts alone imply" [11] (p. 28). Authors sometimes refer to this step when they construct an "overarching metaphor", capturing all metaphors and creating a whole that encompasses all of the included studies. The outcome of our analysis is presented in Table 3.

\subsection{Ethics}

All studies included in the meta-ethnography had received some form of ethical approval in their respective countries.

\section{Results}

This meta-ethnography included ten studies published between 2005 and 2014 (we found no studies published from 2014-2016 that met the inclusion criteria). Three studies were conducted in Australia [16] [17] [21], two in the US [18] [25], two in the UK [20] [24], one in Canada [22], one in New Zealand [23] and one in Sweden [19]. The methodologies used in the studies included some form of thematic analysis, interpretative phenomenological analysis (IPA) or grounded theory. Data were collected by means of individual or focus group interviews. In total, 210 women were included, with samples varying from 5 to 41 participants.

Table 3. Analysis.

\begin{tabular}{|c|c|}
\hline CENTRAL METAPHORS & KEY METAPHORS \\
\hline Feeling trapped by reality & $\begin{array}{l}\text { - experiencing an unexpected change in social role } \\
\text { - losing oneself, losing one's identity } \\
\text { - pressure to succeed, but unable to cope with reality } \\
\text { - must appear to be the perfect mother, but experience of falling } \\
\text { outside social expectations }\end{array}$ \\
\hline $\begin{array}{l}\text { Experiencing a nameless } \\
\text { chaos }\end{array}$ & $\begin{array}{l}\text { - trapped in a black hole, including experiences of sadness, chaos, } \\
\text { loss of control and isolation } \\
\text { - extreme fatigue and isolation prevent them from seeking help } \\
\text { - lack of knowledge about what is happening and whether the } \\
\text { feelings are normal } \\
\text { - unprepared for the extreme feelings }\end{array}$ \\
\hline Struggling to find a way out & $\begin{array}{l}\text { - downward spiral } \\
\text { - the fear of being stigmatized contribute to hiding one's feelings } \\
\text { - difficult to find someone to turn to } \\
\text { - admitting to oneself that it is essential to find help } \\
\text { - important that feelings are given a name }\end{array}$ \\
\hline $\begin{array}{l}\text { Being seen as a normal but } \\
\text { suffering person }\end{array}$ & $\begin{array}{l}\text { - lack of trust and continuity constitutes a barrier to seeking help } \\
\text { - fear of consequences related to being given a diagnosis } \\
\text { - one-to-one support feels good }\end{array}$ \\
\hline
\end{tabular}


The studies described the women's experiences of living with PPD, including coping strategies, but also their reflections on the help they received and their experiences of shame, stigmatization, loneliness and isolation. The studies are presented in Table 4.

Four central metaphors described women's experiences of having PPD: 1) Feeling trapped by reality, 2) Experiencing a nameless chaos, 3) Struggling to find a way out and 4) Being seen as a normal but suffering person. We will present quotations from the primary studies in order to elucidate the findings.

\subsection{Feeling Trapped by Reality}

The women experienced that becoming mothers changed their social role [17] [18] [19] [21]. They described experiences of "losing themselves" and their identity [16] [18] [19] [21]. The changes were related to their employment situation, their social role and their appearance, but also to their sense of autonomy. They found that their expectations of motherhood did not concur with reality and experienced having to set aside their personal needs in order to meet those of the baby [16] [17] [19] [20] [21]. Their experience of coping with motherhood was challenging [16]-[23] [25] and taking care of a newborn child felt overwhelming. They believed that other mothers were "good mothers" [16] [22] [24], which was an extra burden. As a result, it became important for them to demonstrate to the outside world that they were able to cope with their role as a mother, although they experienced falling outside what they believed to be the cultural and societal expectations of motherhood. One of the women described it as follows:

I started to fall to pieces and think I am not coping or doing things right as a mum and that I am failing as a mother. Women I know who are mothers always look sensational and have it all together [23].

\subsection{Experiencing a Nameless Chaos}

The women said they felt that something was wrong before they received a diagnosis. However, some were uncertain about whether their experiences could be characterized as normal [16] [22] [23] [24]. They had no one with whom they could compare themselves, resulting in feelings of confusion that sometimes prevented them from seeking help [23] [25]. Many women said they were unprepared for the fact that they could develop PPD [16] [17] [18] and were unable to compare their own experiences with information about PPD that they found on the Internet. They said that had they received more information about the diagnosis, it would have reduced the feeling of being crazy [20] [23]. The women also reported suffering from constant fatigue. They described experiencing sleep deprivation and felt exhausted and unable to think clearly [17] [18] [19] [21], which also prevented them from seeking help. The constant fatigue resulted in isolation as they were unable to stay in contact with their social network [18] [22] and lacked the energy to care for their children in the way they felt they should [12]. Overall, they considered these changes in their lives to be major, often resulting in feelings of chaos and confusion, mixed with anxiety [16] [21] [23]. 
Table 4. Descriptive characteristics of the included articles.

\begin{tabular}{|c|c|c|c|c|}
\hline $\begin{array}{l}\text { Author, } \\
\text { Year \& } \\
\text { Country }\end{array}$ & Methodology/design & $\begin{array}{l}\text { Sample strategy and } \\
\text { sample size }\end{array}$ & $\begin{array}{l}\text { Data collection } \\
\text { method } \\
\text { Analytic approach }\end{array}$ & Key findings \\
\hline $\begin{array}{l}\text { Bilszta et al. } \\
\text { 2010, Australia }\end{array}$ & $\begin{array}{l}\text { Qualitative, exploring } \\
\text { experiences after having a baby, } \\
\text { recognition of symptoms, } \\
\text { seeking help, treatment } \\
\text { experiences and options } \\
\text { as well as ideal treatment }\end{array}$ & $\begin{array}{l}\text { Participants }(\mathrm{N}=40) \\
\text { were recruited from } \\
\text { either outpatient } \\
\text { depression treatment } \\
\text { programmes or } \\
\text { community-based } \\
\text { mutual } \\
\text { support } \\
\text { programmes }\end{array}$ & $\begin{array}{c}\text { Focus groups } \\
\text { Interpretative } \\
\text { phenomenological } \\
\text { analysis }\end{array}$ & $\begin{array}{l}\text { Lived experiences of } \mathrm{PPD}^{\star} \text { and } \\
\text { associated attitudes and beliefs result } \\
\text { in significant barriers to accessing } \\
\text { help. Eight theme clusters were } \\
\text { identified: expectations of } \\
\text { motherhood, not coping and fear of } \\
\text { failure, stigma and denial, poor } \\
\text { mental health awareness and access, } \\
\text { interpersonal support, baby } \\
\text { management, seeking help, } \\
\text { treatment experiences and } \\
\text { relationships with healthcare } \\
\text { professionals }\end{array}$ \\
\hline $\begin{array}{l}\text { Buultjens \& } \\
\text { Liamputtong, } \\
\text { 2007, Australia }\end{array}$ & $\begin{array}{l}\text { Qualitative } \\
\text { approach }\end{array}$ & $\begin{array}{l}\text { Participants }(\mathrm{N}=10) \\
\text { clinically diagnosed } \\
\text { and admitted to a } \\
\text { mother and baby } \\
\text { unit in a large } \\
\text { hospital }\end{array}$ & $\begin{array}{l}\text { In-depth interviews } \\
\text { Thematic analysis }\end{array}$ & $\begin{array}{l}\text { Three themes emerged: Becoming a } \\
\text { mother: What to expect; The birth of } \\
\text { the baby; The experiences of the } \\
\text { hospital stay and Perceptions of } \\
\text { causes and experiences of PPD. } \\
\text { Stigma is frequently attached to } \\
\text { women who are unhappy after the } \\
\text { birth of a child because they are not } \\
\text { coping with the demands of } \\
\text { motherhood or do not instantly } \\
\text { bond with and love their baby. } \\
\text { PPD is a terrifying and isolating } \\
\text { experience for women }\end{array}$ \\
\hline $\begin{array}{c}\text { Dennis \& } \\
\text { Moloney, 2009, } \\
\text { USA }\end{array}$ & $\begin{array}{c}\text { Phenomenological } \\
\text { approach }\end{array}$ & $\begin{array}{l}\text { Five participants } \\
\text { were recruited by } \\
\text { professional and } \\
\text { personal colleague } \\
\text { referrals and from a } \\
\text { poster placed in the } \\
\text { offices of two } \\
\text { physicians }\end{array}$ & $\begin{array}{l}\text { Thematic analysis } \\
\text { Qualitative interviews } \\
\text { were conducted }\end{array}$ & $\begin{array}{c}\text { Four themes emerged: No idea it } \\
\text { would happen to me, Losing myself, } \\
\text { A bad place to be and Working } \\
\text { through }\end{array}$ \\
\hline $\begin{array}{l}\text { Edhborg et al. } \\
2005 \text {, Sweden }\end{array}$ & Grounded theory & $\begin{array}{l}\text { Twenty-two women } \\
\text { were recruited from a } \\
\text { group of } \mathrm{N}=224\end{array}$ & $\begin{array}{l}\text { Data were analysed } \\
\text { using the constant } \\
\text { comparative method } \\
\text { and coded on three } \\
\text { levels. } \\
\text { Data were collected by } \\
\text { means of interviews in } \\
\text { the family home }\end{array}$ & $\begin{array}{l}\text { The results showed that the new } \\
\text { mothers struggled with life in terms } \\
\text { of themselves, their child and their } \\
\text { partner. They expressed feelings of } \\
\text { loss of who they are, felt } \\
\text { overwhelmed by responsibility for } \\
\text { the child and struggled with feelings } \\
\text { of abandonment, worries, and } \\
\text { breastfeeding problems }\end{array}$ \\
\hline Hall 2006, UK & Phenomenological approach & $\begin{array}{l}\text { Ten women were } \\
\text { interviewed }\end{array}$ & $\begin{array}{c}\text { Interpretative } \\
\text { phenomenological } \\
\text { analysis. } \\
\text { Unstructured } \\
\text { interviews were } \\
\text { conducted }\end{array}$ & $\begin{array}{l}\text { The results revealed themes } \\
\text { concerning difficulties pertaining to } \\
\text { disclosure, telling people about their } \\
\text { thoughts and feelings, expectations } \\
\text { and motherhood, beliefs around } \\
\text { being a bad mum and issues } \\
\text { associated with attachment }\end{array}$ \\
\hline
\end{tabular}




\section{Continued}

Highet et al.

2014,

Australia

Phenomenological approach
They were recruited via the "beyondblue" website and contact lists where people had registered their details and expressed an interest in participating in research projects
Grounded theory perspective.

Face-to-face $(\mathrm{n}=24)$ and telephone interviews $(\mathrm{n}=4)$ with women who had experienced PPD
Qualitative data were collected on support needs, the availability of resources, perceived barriers to support and support preferences of

41 women were

$\begin{array}{cc}\text { Letourneau et } & \text { Explorative } \\ \text { al. 2007, } & \text { descriptive } \\ \text { Canada } & \text { approach }\end{array}$

McCarthy \&

$\begin{array}{cc}\text { McMahon } & \text { Explorative } \\ 2008, & \text { approach }\end{array}$

New

Zealand

$\begin{array}{cc}\text { Slade et al. } & \text { Explorative } \\ 2010, & \text { approach }\end{array}$

Williams 2013, Qualitative, naturalistic inquiry USA included in the study

Fifteen women who had received

treatment and support for PND

from the community mental health

services

participated

Thirty women

recruited from a

randomized

controlled trial

Nine women who

were medically

diagnosed with PND

and self-identified as recovered from PND

The central phenomenon was called Loss and Frustration based on three themes: Pregnancy and motherhood-related changes, Disappointment about the pregnancy and motherhood experience and The experience of symptoms of depression and anxiety

Mothers' need for support included help with the household, assistance with the baby and informational support. Affirmational support was perceived as best received from someone who understood or appreciated their experiences, such as a mother who had also suffered from PPD.

However, household, baby and informational needs must be met before emotional and affirmational needs are addressed

The majority of the women had experienced a "crisis point" before seeking help and treatment due to the stigma attached to feelings of inability to cope and being a "bad mother". The women were unable to differentiate between "normal" levels of postpartum distress and depressive symptoms that might require intervention

Three themes emerged: Seeking help, Roles and relationships and Experiences of intervention or support

Constant comparison of data for discovery of thematic junctures Interviews
Four themes emerged: Prelude to recovery, Igniting recovery, Recovery as a victory and Realizing recovery

${ }^{\star} \mathrm{PPD}=$ Postpartum depression. 
They were lonely and unable to experience feelings of joy, they felt trapped in a "black hole" [16] [19] [22] [24] [25]. The feelings connected to the PPD outbreak were intense and unlike anything they had experienced before [22] [23] [25]. One of the participants in Dennis and Moloney's [18] study described her feelings as follows:

It was like I couldn't find myself; I had lost myself. I can remember that more than anything; standing there looking in the mirror and saying I don't know you, who are you? [18].

\subsection{Struggling to Find a Way Out}

The women described the disorder as a downward spiral where one problem led to another [18]. Feelings of shame and fear of being stigmatized contributed to the fact that some chose to conceal their disorder [16] [23] [24]. According to several women, their family's attitude towards PPD was of vital importance for their decision to seek help [17]. Although they needed to talk to someone about their situation, they rarely turned to their partner, family or friends [19] [22] as they sensed that they lacked knowledge and understanding about the disorder. Sometimes, this lack of knowledge and understanding resulted in people trying to justify or explain away the disorder, rather than acknowledging their pain [20] [22]. However, at some point the women had to admit that they needed help [24] [25] and that they had to take responsibility for it themselves. This was difficult, as they felt a failure as a mother and unfit to care for their children [18] [22] [24]. However, when they reached this crisis point they felt more energetic and developed new coping strategies [25], e.g., strategies for managing everyday chores. They perceived that when their feelings and experiences were given a name they felt less guilt and shame. They said they would like to share these experiences with other women [23] [25]. One of the women described recovery as follows:

But then you have to recover, you have no choice after a while. I think once I started feeling like my old self, you have to say, ah, I don't want to feel like this anymore. And really get your head back in the game. I think it is up here (pointing to forehead) as far as just trying to change yourself [25].

\subsection{Being Seen as a Normal but Suffering Person}

The women were reluctant to inform healthcare providers about their situation as they were afraid of being admitted to hospital and having their baby removed from their care [18] [20]. They had no knowledge about where to go or who they should approach to ask for help [17] [19]. Some described their relationship with healthcare professionals as arduous and a barrier to seeking help [24], while others stated that they did not trust the public health nurse or did not believe that she understood their situation [16]. They described a lack of continuity in maternity care and the difference they had experienced between pre- and postnatal care [16] [24]. Some women complained about healthcare professionals 
making condescending remarks and several reported that healthcare professionals trivialized their situation. This resulted in increased experiences of guilt and low self-esteem [16] [22] [24]. However, some found one-to-one support from healthcare professionals helpful, while others preferred telephone support or self-help groups [22]. Several considered that the use of a depression-screening instrument like the EPDS (Edinburgh Postnatal Depression Scale) [27]was positive as it focused on themselves and their disorder instead of the baby [24]. Others felt ashamed that they required medical treatment and a good relationship with healthcare professionals was considered important for ensuring proper treatment and care [16]. One of the women in McCarthy and McMahon's study [23] described her emotions related to the diagnosis as follows:

It wasn't probably the advice that she gave me, it was just knowing that someone else had been through what I had been through. I wasn't a weirdo, I wasn't a nutter, I wasn't a freak, I was just a normal person suffering what mums, some mums suffer [23].

\section{Synthesis}

The aim of the study was to explore and synthesize qualitative empirical studies published between 2005 and 2016 that describe women's experiences of postpartum depression.

Four central metaphors were generated from the analysis and resulted in the following synthesis:

The women expected the transition to motherhood to be a joyous experience. However, they found it painful, lonely and experienced losing themselves in a nameless chaos. This resulted in feelings of sadness, anxiety, shame and guilt.

\section{Discussion}

The transition to motherhood is a major life event and makes the woman's mental health vulnerable [28]. According to Stern [29], a mother is born psychologically when a woman gives birth to a child and he describes the transition to motherhood as a process involving changes on various levels, including identity. Thus, from a psychological perspective, it takes time for a woman to become a mother [30]. The women in the present study described feelings of vulnerability related to their maternal identity. This is easy to understand, given the fact that a woman's status and identity in life changes overnight with the birth of her first baby [29]. Thus, for some women the time following birth is characterized by frustration and despair [30] [31].

Haga and co-workers [28] discussed the significance of women's mental attitude when confronted with a new role. They found that women who are used to being in control of their everyday life often have high expectations related to childbearing and motherhood. When these expectations do not correspond with reality, they sometimes end up becoming frustrated or depressed. This is in accordance with the present findings describing women's experiences of losing 
control or "losing themselves". Becoming a mother was overwhelming and not what they had expected. Similar findings were reported by Beck [9], who stated that "pervasive loss" was one of the main findings in her study. We argue that for many women, the social construction of motherhood is closely tied to the image of the "perfect mother", presented in the media as a correct way to understand motherhood. For some mothers, this may result in experiences of being unable to live up to their own (as well as what they believe to be others) expectations of motherhood. At the same time, the women described losing their pre-pregnancy identity. They miss the work, social life, body and appearance that they had before they became pregnant. They stated that their pre-pregnancy lives have been set on hold, leaving them in an emotional limbo. In view of recent media discussions about perfectionism related to body image and motherhood, we question whether this is a factor that possibly contributes to more women today experiencing falling outside of or being unable to fulfil society's image of the ideal mother.

Keeping up appearances, giving the impression of being a perfect mother and coping with the expectations related to their role as a mother were important for the women in this study, thus they made an effort to appear normal despite feeling that something was wrong. Stigma is a concept referring to an "attribute that is deeply discrediting" [32] (p. 13). A socially stigmatized person differs from the cultural norms in society and suffering from a mental disorder is one reason for being discredited or socially stigmatized. In this case, mothers suffering from mental disorders describe falling outside what they perceive to be the societal norm of motherhood. Many are uncertain about their feelings and avoid sharing them with family and friends for fear of being considered unfit to be mothers and receiving negative reactions from people in their surroundings [33]. This strategy is likely to involve fear of disclosure, resulting in feelings of shame about having a mental disorder. Our findings demonstrate that good quality social support is of vital importance for recovering from PPD and coping with everyday life, which is confirmed by other studies [34] [35]. However, many women described having to reach a crisis point before they were able to share their feelings with healthcare professionals. At this point they admitted to themselves that they needed help to recover, which was a first step towards breaking down their wall of isolation and solitude.

\section{Limitations}

In order to determine transferability, it is vital to consider the range of empirical variation in the sample [36]. This meta-ethnographic study includes ten primary studies with a total sample of 210 women from six different countries/continents. However, the majority of the participants were Caucasian and we are aware that this probably influenced the results. On the other hand, the included articles contain findings from rural and urban areas, which strengthen transferability. We consider the chosen design useful and relevant, and the ten included prima- 
ry studies provided us with sufficient empirical power to broadly elucidate the research question [37]. We performed a literature search in collaboration with an experienced librarian, but accept that the search terms and inclusion and exclusion criteria may have influenced the study's internal validity and that new studies about women's experiences of PPD may have been published after our search was conducted. Quality appraisal of the studies was guided by a checklist [26], but detailed scoring of the papers was not performed. Noblit and Hare [11] outlined seven steps to guide the researcher when conducting a meta-ethnography, but did not define the analytic process of synthesizing and provided no guidance about if/how sampling and appraisal should be undertaken [11]. In this study, we synthesized across methodologies [38] and found it uncomplicated. According to Zimmer [39], some methodologies are more compatible than others due to their epistemological stance. Thus, it is possible to synthesize across methodologies if one takes the differences in methodological assumptions underpinning the studies into consideration. Thorne [13] argues that when conducting a qualitative meta-synthesis, the use of detailed guidelines, such as COREQ (Consolidated Criteria for Reporting Qualitative Research) [40], is unlikely to increase the reporting quality, particularly in terms of the analysis and synthesis process and study output. In this study we did not use a checklist intended for scoring. However, the included papers were considered to be of medium or good quality based on the CASP checklist. We acknowledge that only four out of ten studies include a reflexivity discussion and are aware that this may have influenced the results. Meta-ethnography aims at contributing an increased understanding of a phenomenon that exceeds the sum of the findings in the primary studies [41]. We included studies published within a short time span (2005-2014) and several of our findings coincide with findings in previous meta-studies [9] [10]. However, the included papers described challenges related to identity and role, and we ask if these challenges are somehow related to changes in society and an altered understanding of the concept of motherhood.

\section{Conclusions}

Postpartum depression affects a new mother at a crucial point, occurring when she expects to experience joy and happiness rather than chaos, sadness and despair. Thus, PPD may result in feelings of shame and stigma. Consequently, it is important to increase the level of knowledge about the disorder for all parties involved. Furthermore, it is essential to gain social acceptance for the fact that the transition to motherhood can be a strenuous, stressful and difficult period for some women.

Few mothers with depressive symptoms require treatment from specialist health services. Midwives and physicians are in an ideal position to provide pregnant women with adequate information about the disorder and identify symptoms of depression. Screening tools, such as the EPDS, may be useful for diagnosing postpartum depression, but should be supported by clinical judge- 
ment and involve a discussion regarding when, how and by whom the screening should be conducted. Various interventions should be offered to women suffering from PPD, including pharmacological as well as non-pharmacological options such as group support and one-to-one support provided by competent healthcare professionals. Such interventions require sound collaboration between the professional categories within maternity care.

\section{Acknowledgements}

The authors would like to thank Monique Federsel for proofreading the English language.

\section{Funding Statement}

We acknowledge that the study was supported by a grant from the Centre for Women's, Family \& Child Health, Faculty of Nursing and Health Sciences, University of Southeast Norway, Kongsberg, Norway.

\section{Authors' Contributions}

M.S.H and B.D were responsible for the study design, data collection and analysis. M.S.H was responsible for writing the initial manuscript. All authors contributed intellectually, proof read and approved the final manuscript. B.D supervised the study.

\section{References}

[1] Brockington, I. (2004) Postpartum Psychiatric Disorders. Lancet, 363, 303-310. https://doi.org/10.1016/S0140-6736(03)15390-1

[2] Stewart, D.E. and Vigod, S. (2016) Postpartum Depression. The New England Journal of Medicine, 375, 2177-2186. https://doi.org/10.1056/NEJMcp1607649

[3] World Health Organization (2010) WHO ICD-10. International Statistical Classification of Diseases, 10th Revision. http://apps.who.int/classifications/icd10/browse/2010/en\#/F53.0

[4] American Psychiatric Association (2013) Diagnostic and Statistical Manual of Mental Disorders. 5th Edition, DSM-5. American Psychiatric Publishing, Arlington, 155-233. https://doi.org/10.1176/appi.books.9780890425596

[5] Eberhard-Gran, M., Slinning, K. and Rognerud, M. (2014) Screening for Postpartum Depression-A Literature Search. Journal of the Norwegian Medical Association, 134, 297-301.

[6] Fredriksen, E., von Soest, T., Smith, L. and Moe, V. (2017) Patterns of Pregnancy and Postpartum Depressive Symptoms: Latentclass Trajectories and Predictors. Journal of Abnormal Psychology, 126,173-183. https://doi.org/10.1037/abn0000246

[7] Munk-Olsen, T., Laursen T.M., Pedersen, C.B., Mors, O. and Mortensen, P.B. (2006) New Parents and Mental Disorders: A Population-Based Register Study. JAMA, 296, 2582-2589. https://doi.org/10.1001/jama.296.21.2582

[8] Stein, A., Pearson, R.M., Goodman, S.H., Rapa, E., Rahman, A., McCallum, M., Howard, L.M. and Pariante, C.M. (2014) Effects of Perinatal Mental Disorders on the Fetus and Child. Lancet, 384, 1800-1819. 
https://doi.org/10.1016/S0140-6736(14)61277-0

[9] Beck, C.T. (2002) Postpartum Depression: A Metasynthesis. Qualitative Health Research, 12, 453-472. https://doi.org/10.1177/104973202129120016

[10] Knudson-Martin, C. and Silverstein, R. (2009) Suffering in Silence: A Qualitative Meta-Data-Analysis of Postpartum Depression. Journal of Marital Family Therapy, 35, 145-158. https://doi.org/10.1111/j.1752-0606.2009.00112.x

[11] Noblit, G.W. and Hare, R.D. (1988) Meta-Ethnography: Synthesizing Qualitative studies. Sage Publications, Newbury Park. https://doi.org/10.4135/9781412985000

[12] France, E.F., Ring, E., Thomas, R., Noyes, J., Maxwell, M. and Jepson, R. (2014) A Methodological Systematic Review of What's Wrong with Meta-Ethnography Reporting. BMC Medical Research Methodology, 14, 119.

https://doi.org/10.1186/1471-2288-14-119

[13] Thorne, S. (2017) Metasynthetic Madness: What Kind of Monster Have We Created? Qualitative Health Research, 27, 3-12. https://doi.org/10.1177/1049732316679370

[14] Sandelowski, M. and Barroso, J. (2006) Handbook for Synthesizing Qualitative Research. Springer Publishing Company, New York.

[15] Moher, D., Liberati, A., Tetzlaff, J. and Altman, D.G. (2009) Preferred Reporting Items for Systematic Reviews and Meta-Analyses: The PRISMA Statement. BMJ, 339, b2535. https://doi.org/10.1136/bmj.b2535

[16] Bilszta, J., Ericksen, J., Buist, A. and Milgrom, J. (2010) Women's Experience of Postnatal Depression-Beliefs and Attitudes as Barriers to Care. Australian Journalof Advanced Nursing, 27, 44-54.

[17] Buultjens, M. and Liamputtong, P. (2007) When Giving Life Starts to Take the Life out of You: Women's Experiences of Depression after Childbirth. Midwifery, 23, 77-91. https://doi.org/10.1016/j.midw.2006.04.002

[18] Dennis, T. and Moloney, M. (2009) Surviving Postpartum Depression and Choosing to Be a Mother. Southern Online Journal of Nursing Research, 9, 8.

[19] Edhborg, M., Friberg, M., Lundh, W. and Widström, A.M. (2005) Struggling with Life: Narratives from Women with Signs of Postpartum Depression. Scandinavian Journal of Public Health, 33, 261-267. https://doi.org/10.1080/14034940510005725

[20] Hall, P. (2006) Mothers' Experiences of Postnatal Depression: An Interpretative Phenomenological Analysis. Community Practitioner, 79, 256-260.

[21] Highet, N., Stevenson, A., Purtell, C. and Coo, S. (2014) Qualitative Insights into Women's Personal Experiences of Perinatal Depression and Anxiety. Women Birth, 27, 179-184. https://doi.org/10.1016/j.wombi.2014.05.003

[22] Letourneau, N., Duffett-Leger, L., Stewart, M., Hegadoren, K., Dennis, C.L., Rinaldi, C.M. and Stoppard, J. (2007) Canadian Mothers' Perceived Support Needs during Postpartum Depression. Journal of Obstetric Gynecology Neonatal Nursing, 36, 441-449. https://doi.org/10.1111/j.1552-6909.2007.00174.x

[23] McCarthy, M. and McMahon, C. (2008) Acceptance and Experience of Treatment for Postnatal Depression in a Community Mental Health Setting. Health Care Women International, 29, 618-637. https://doi.org/10.1080/07399330802089172

[24] Slade, P., Morrell, C.J., Rigby, A., Ricci, K., Spittlehouse, J. and Brugha, T.S. (2010) Postnatal Women's Experiences of Management of Depressive Symptoms: A Qualitative Study. British Journal of General Practice, 60, 440-448.

https://doi.org/10.3399/bjgp10X532611 
[25] Williams, P. (2013) Mothers' Descriptions of Recovery from Postpartum Depression. MCN The American Journal of Maternal Child Nursing, 38, 276-281. https://doi.org/10.1097/NMC.0b013e3182993fbf

[26] Critical Appraisal Skills Programme (2017) CASP (Qualitative Research) Checklist. http://www.casp-uk.net/casp-tools-checklists

[27] Cox, J.L., Holden, J.M. and Sagovsky, R. (1987) Detection of Postnatal Depression. Development of the 10-Item Edinburgh Postnatal Depression Scale. British Journal of Psychiatry, 150, 782-786. https://doi.org/10.1192/bjp.150.6.782

[28] Haga, S.M., Lynne, A., Slinning, K. and Kraft, P. (2012) A Qualitative Study of Depressive Symptoms and Well-Being among First-Time Mothers. Scandinavian Journal of Caring Science, 26, 458-466. https://doi.org/10.1111/j.1471-6712.2011.00950.x

[29] Stern, D.N. (1995) The Motherhood Constellation: A Unified View of Parent-Infant Psychotherapy. Karnac Books, London.

[30] Stern, D.N., Bruschweiler-Stern, N. and Freeland, A. (1998) The Birth of a Mother. How the Motherhood Experiences Changes You Forever. Basic Book, New York.

[31] Brudal, L.F. (2000) Psykiske Reaksjoner ved Svangerskap, Fødsel og Barseltid. Fagbokforlaget, Bergen.

[32] Goffman, E. (1986) Stigma: Notes on the Management of Spoiled Identity. Simon \&Schuster, New York.

[33] Norvoll, R. (2002) Samfunn og Psykiske Lidelser: Samfunnsvitenskapelige Perspektiver-En Introduksjon. Gyldendal Akademisk, Oslo.

[34] Evans, M., Donelle, L. and Hume-Loveland, L. (2012) Social Support and Online Postpartum Depression Discussion Groups: A Content Analysis. Patient Education Counselling, 87, 405-410. https://doi.org/10.1016/j.pec.2011.09.011

[35] Xie, R.H., He, G., Koszycki, D., Walker, M. and Wen, S.W. (2009) Prenatal Social Support, Postnatal Social Support and Postpartum Depression. Annals of Epidemiology, 19, 637-643. https://doi.org/10.1016/j.annepidem.2009.03.008

[36] Malterud, K. (2001) Qualitative Research: Standards, Challenges and Guidelines. The Lancet, 358, 483-488. https://doi.org/10.1016/S0140-6736(01)05627-6

[37] Malterud, K., Siersma, V.D. and Guassora, A.D. (2015) Sample Size in Qualitative Interview Studies: Guided by Information Power. Qualitative Health Research, 26, $1-8$.

[38] Jensen, L.A. and Allen, M.N. (1996) Meta-Synthesis of Qualitative Findings. Qualitative Health Research, 6, 553-560. https://doi.org/10.1177/104973239600600407

[39] Zimmer, L. (2006) Qualitative Meta-Synthesis: A Question of Dialoguing with Texts. Journal of Advanced Nursing, 53, 11-18. https://doi.org/10.1111/j.1365-2648.2006.03721.x

[40] Tong, A., Sainsbury, P. and Craig, J. (2007) Consolidated Criteria for Reporting Research (COREQ): A 32-Item Checklist for Interviews and Focus Groups. International Journal for Quality in Health Care, 19, 349-357. https://doi.org/10.1093/intqhc/mzm042

[41] Bondas, T. and Hall, E.O.C. (2007) Challenges in Approaching Metasynthesis Research. Qualitative Health Research, 17, 113-121. https://doi.org/10.1177/1049732306295879 
Submit or recommend next manuscript to SCIRP and we will provide best service for you:

Accepting pre-submission inquiries through Email, Facebook, LinkedIn, Twitter, etc. A wide selection of journals (inclusive of 9 subjects, more than 200 journals)

Providing 24-hour high-quality service

User-friendly online submission system

Fair and swift peer-review system

Efficient typesetting and proofreading procedure

Display of the result of downloads and visits, as well as the number of cited articles Maximum dissemination of your research work

Submit your manuscript at: http://papersubmission.scirp.org/

Or contact ojn@scirp.org 